\title{
Management of acute bronchiolitis
}

\author{
Karl Rakshi, Jonathan M Couriel
}

As winter approaches, paediatricians steel themselves for the annual flood of babies with acute bronchiolitis. It is the commonest lower respiratory tract infection in infants. Around $10 \%$ of babies develop bronchiolitis in their first year and a fifth of these are admitted to hospital. ${ }^{1}$ In this children's hospital between 200 and 260 infants are admitted with the disease each winter. The epidemic imposes great strains on the hospital: for example, in the first eight weeks of 1993, there were 179 admissions of infants with bronchiolitis, with a mean length of stay of 4.5 days. We ventilate 12-25 babies for bronchiolitis each winter: they occupy a total of 70-190 days a year on the intensive care unit.

Many aspects of management remain controversial. For example, what is the most reliable way of assessing the severity of bronchiolitis? What is the role of electronic monitoring, or ribavirin (tribavirin), of physiotherapy? Are bronchodilators helpful? If babies cannot feed, should they be given intravenous or nasogastric fluids? Which babies need intensive care? How can we reduce cross infection? In this paper we examine these and other controversies in the care of the child with bronchiolitis.

\section{Aetiology and pathophysiology}

It is helpful to have a clear understanding of the aetiology and pathophysiology of bronchiolitis. Acute bronchiolitis is due to viral colonisation of the bronchiolar mucosa. Respiratory syncytial virus (RSV) is the pathogen in $70-85 \%$ of cases, the remainder being caused by parainfluenza, influenza, and adenoviruses. ${ }^{12}$ Dual infection with other viruses, or organisms such as Chlamydia trachomatis or Mycoplasma pneumonia, is more common than previously thought, occurring in at least $5-10 \%$ of cases of RSV lower respiratory infection. ${ }^{34}$

The virus replicates rapidly in the bronchiolar epithelium, causing necrosis of the ciliated cells and proliferation of non-ciliated cells. The ciliary damage impairs clearance of secretions. This, combined with increased mucus secretion and desquamation of cells, leads to bronchiolar obstruction, atelectasis, and hyperinflation. The peribronchial tissues show inflammatory infiltration, submucosal oedema, and congestion. An associated interstitial pneumonia may occur. Structural recovery usually occurs in two to three weeks.
Occasionally, and particularly if adenovirus serotype 7 or 21 is the pathogen, there is permanent bronchiolar damage with persistent segmental or lobar atelectasis and hyperinflation (bronchiolitis obliterans).

The acute functional consequences of these changes are small airways obstruction, gas trapping, and impaired gas exchange. Thoracic gas volume and respiratory resistance rise, and expiratory flow rates and dynamic compliance fall. ${ }^{125}$ The work of breathing and oxygen consumption are increased. 6 Impaired ventilation, combined with ventilation perfusion imbalance, and in some infants, hypoventilation due to apnoea or exhaustion, lead to hypoxaemia and hypercarbia. ${ }^{178}$

\section{Diagnosis}

Accurate diagnosis is based on the clinical features. Fever and a nasal discharge precede a dry cough and increasingly rapid, distressed breathing. Wheezing is often, but not always, audible. Feeding difficulties due to dyspnoea are often the reason for admission. Central apnoea with cyanosis is seen in $10-20 \%$ of babies admitted with bronchiolitis. ${ }^{9-11}$ Apnoea usually occurs early in the illness: it can be the presenting feature, preceding the features of airways obstruction.

Examination reveals tachycardia and tachypnoea, with subcostal, intercostal, and supraclavicular recession. Unlike the breathing pattern seen in croup or pneumonia, there is little sternal recession, as gas trapping prevents this. The sternum is prominent, the chest appears barrel shaped, and the liver is displaced downwards, indicating hyperinflation. The child has a short, dry, wheezy cough. There are fine inspiratory crackles and/or high pitched expiratory wheezes in all lung fields. In severe cases there may be irregular breathing, cyanosis or pallor. Fever is present in most infants; conjunctivitis, pharyngitis, or otitis media in a minority.

\section{Identifying the high risk infant}

Certain infants are at high risk of severe illness, respiratory failure requiring ventilatory support, and of dying with bronchiolitis (table 1). Children with chronic lung disease, congenital heart disease, or immunodeficiency are at particularly high risk. ${ }^{12-15}$ Infants aged less than 6 weeks and those born prematurely are also at risk: apnoea is common in these babies. ${ }^{9}$ 
Table 1 Risk factors for severe bronchiolitis

$$
\begin{aligned}
& \text { Age less than } 6 \text { weeks at presentation } \\
& \text { Apnoea } \\
& \text { Preterm birth } \\
& \text { Underlying disorders } \\
& \text { Lung disease (for example bronchopulmonary dysplasia, } \\
& \text { cystic fibrosis) } \\
& \text { Congenital heart disease } \\
& \text { Immunodeficiency (congenital or acquired) } \\
& \text { Multiple congenital abnormalities } \\
& \text { Severe neurological disease }
\end{aligned}
$$

In a case-control study of 33 infants ventilated for RSV bronchiolitis and 99 infants positive for RSV who were not ventilated, 39\% of the ventilated infants had apnoea before admission and $63 \%$ had apnoea before ventilation was started (T G Powell, J M Couriel, unpublished data). Apnoea was significantly more frequent in infants born prematurely. The median postconceptional age was 19 days in the ventilated group and 122 days in the controls. Over $90 \%$ of the ventilated infants weighed less than $5 \mathrm{~kg}$ on admission. Others have shown that low birth weight, preterm delivery, neonatal respiratory disease, and young age are all risk factors for respiratory failure. ${ }^{16}$ Infants with any of these factors need close observation.

\section{Differential diagnosis}

Other conditions can mimic bronchiolitis and may easily be overlooked (table 2). For example, we have seen children with previously unsuspected cystic fibrosis, aspiration pneumonitis, congenital cardiac and lung defects, and immune deficiency, with a misdiagnosis of bronchiolitis. Careful attention to the preceding history, examination, and chest radiograph usually allows other causes to be identified. It may be impossible to distinguish between the first episode of asthma and acute bronchiolitis

Even when the diagnosis of bronchiolitis is certain, an underlying congenital abnormality or dual infection should be considered if the illness is severe, prolonged, or atypical. For example, babies with congenital heart defects, and particularly those with pulmonary hypertension, may be asymptomatic until they develop bronchiolitis, when they deteriorate rapidly.

\section{Investigations}

Investigations often add little to management. A chest radiograph typically shows hyperinflation, with depressed and flattened diaphragms. A third of infants have collapse or consolidation, particularly in the upper lobes. Unfortunately, there is no correlation between these findings and the severity of the illness. ${ }^{17}$ It has been suggested that chest radiographs should not be done routinely in bronchiolitis: they should be reserved for infants with severe disease, sudden deterioration, or an underlying cardiac or respiratory disorder. ${ }^{17}$ Full blood counts and serum electrolytes are normal in over $80 \%$ of children admitted with bronchiolitis. ${ }^{18}$ Electrolyte disturbances, most notably hyponatraemia, are uncommon unless there is severe disease. ${ }^{19} 20$ Arterial blood gases
Table 2 Differential diagnosis of acute bronchiolitis

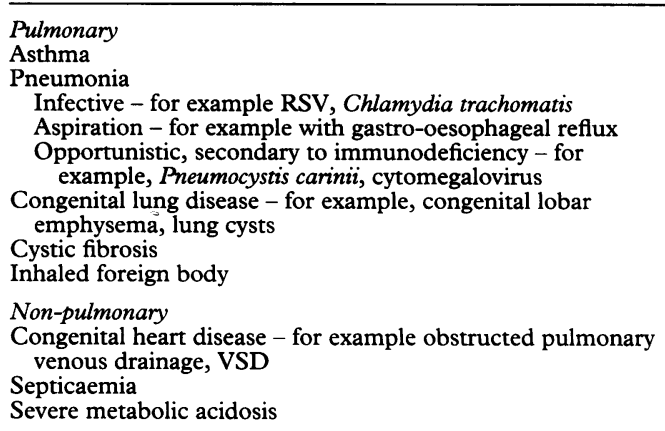

VSD $=$ ventricular septal defect.

should be performed only in severe cases. Arterial carbon dioxide levels may be above $10 \mathrm{kPa}$ in infants admitted to hospital. ${ }^{17}$

Respiratory syncytial virus and the other respiratory viruses can be identified by fluorescent antibody techniques or by culture of nasopharyngeal secretions. Although rapid viral identification has been used to isolate children positive for $\mathrm{RSV},{ }^{21}$ the lack of a positive result does not preclude a diagnosis of bronchiolitis or affect outcome. Viral identification is desirable rather than essential

\section{Assessing and monitoring severity}

Hypoxia is the most vital physiological consequence of bronchiolitis. However, hypoxia can be difficult to detect clinically in infants with respiratory infections. ${ }^{22}$ Few clinical scores for bronchiolitis have been validated against arterial oxygen levels. Mulholland et al compared blood gases with oxygen saturation $\left(\mathrm{SaO}_{2}\right)$ measured by pulse oximetry and clinical signs in infants with bronchiolitis. ${ }^{8}$ Crackles and cyanosis correlated with arterial oxygen but respiratory rate, heart rate, and recession did not predict hypoxaemia. Others have found that clinical signs correlate poorly with hypoxaemia. ${ }^{72-24}$ Pulse oximetry is the most reliable method to assess the severity of illness and the oxygen needs in bronchiolitis.

Pulse oximeters are not universally available, and serial clinical assessments are still essential to monitor the progress of the disease. Pulse oximetry also has important limitations. ${ }^{25-27}$ Serious errors in $\mathrm{SaO}_{2}$ can occur with poor application of the sensor, especially if there is a gap between sensor and skin so that light bypasses the tissue bed. ${ }^{26}$ Significant hypoxaemic episodes may be missed with the movement artefact that can occur during crying or procedures. ${ }^{27}$ Oximetry can be unreliable if there is anaemia, hypotension, or hypothermia. Different makes of pulse oximeter have different normal values. Monitors are inaccurate once the $\mathrm{SaO}_{2}$ falls below $80 \%$. Nevertheless, the advantages of oximeters in providing continuous, instantaneous, and non-invasive measures of arterial oxygen levels far outweigh their limitations.

We routinely measure $\mathrm{SaO}_{2}$ at presentation in all infants with bronchiolitis. We also monitor $\mathrm{SaO}_{2}$ continuously in infants with 
moderate-severe disease, and particularly all those receiving oxygen or with risk factors (table 1). In young infants and those born preterm, we also use respiration monitors (Graseby MR10) to detect central apnoea.

\section{Preventing cross infection}

Many children who are admitted to hospital without RSV infection acquire the disease from other infants. Cross infection is an important cause of morbidity and death, particularly in children with pre-existing cardiorespiratory disease. Cross infection rates of $15-30 \%$ have been recorded with RSV. ${ }^{28}$ The virus is shed in large quantities in respiratory secretions and is easily passed from patient to patient. The hands of health professionals and family members are the most important vectors; droplet spread is less important.

One careful study showed that a combination of rapid virus identification, cohort nursing, and the use of gowns and gloves reduced the cross infection rate from $26 \%$ to $9 \% .^{21}$ In this study, isolation of RSV positive babies and handwashing were ineffective by themselves. Others have found isolation and handwashing to be effective in reducing hospital acquired RSV infections and have stated that virus identification, gloves, and gowns are unnecessary. ${ }^{29} 30 \mathrm{We}$ use isolation and handwashing.

\section{Treatment}

Many different forms of treatment are used in the care of infants with acute bronchiolitis: most are of unproved or limited benefit. Adequate hydration and oxygenation, minimal handling, and the early recognition and treatment of complications are the foundation of good care.

\section{FLUIDS}

Despite poor feeding, severe dehydration is uncommon in bronchiolitis. Hyponatraemia due to increased secretion of antidiuretic hormone does occur in RSV infections, particularly in infants with high levels of carbon dioxide tension and those needing ventilation. ${ }^{19} 20 \mathrm{We}$, and others, have seen seizures and severe recurrent apnoeas associated with hyponatraemia. ${ }^{19}$ Fluid intake should be restricted to two thirds of the normal daily allowance and electrolyte concentrations carefully monitored in all infants with severe bronchiolitis. ${ }^{20}$

Practices differ in the way that fluids are given to infants who cannot feed adequately. In theory, obstructing a nostril increases respiratory resistance and the work of breathing and should be avoided in respiratory distress. A dilated stomach may further embarrass ventilation. In practice, many infants with mild-moderate bronchiolitis tolerate a nasogastric tube satisfactorily. If the passage of a tube increases respiratory distress, then it should be removed. In sick children receiving oxygen, those with very rapid respiratory rates, or those with apnoeas, we give fluids intravenously.

\section{OXYGEN}

Oxygen is the only agent that consistently reduces hypoxaemia in bronchiolitis. As described already, clinical assessment is of limited reliability in detecting hypoxaemia: ideally, the amount of oxygen an infant requires should be assessed by their $\mathrm{SaO}_{2}$ levels. We aim to maintain the $\mathrm{SaO}_{2}$ above 93-95\% and adjust the inspired oxygen concentration accordingly. Oxygen should be warm and humidified. It can be delivered into a headbox or tent. Some babies tolerate facemasks or short nasal prongs poorly. Nasopharyngeal oxygen is effective in children with respiratory distress, ${ }^{31}$ but has not been assessed specifically in acute bronchiolitis.

\section{BRONCHODILATORS}

The value of bronchodilators in bronchiolitis remains controversial. In North America, nebulised $\beta$ agonists or adrenaline are widely used, ${ }^{32}$ but in Britain they are regarded as ineffectual. ${ }^{33-5}$ These views reflect differences in definition of the disease: many American studies of bronchiolitis include children who would be diagnosed as having asthma in the UK. ${ }^{135}$

Several studies have shown improved lung mechanics after bronchodilators. Soto et al found a significantly improved specific conductance in $30 \%$ of infants with RSV bronchiolitis given nebulised salbutamol. ${ }^{36}$ Tepper et al showed improved expiratory flow rates with orciprenaline in some infants. ${ }^{37}$ In infants ventilated for bronchiolitis, nebulised isoetharine improved expiratory flow. ${ }^{38}$ Nebulised ipratropium bromide reduced the work of breathing in bronchiolitis, but produced no clinical improvement. ${ }^{639}$

The clinical response to bronchodilators has also been studied. Two studies of children with wheeze showed a transient improvement in some respiratory signs after nebulised salbutamol. ${ }^{4041}$ However, these studies included children up to the age of 21 months, only half the subjects had proved RSV infection, and the studies lasted only 2-4 hours. Wang et al showed no improvement in $\mathrm{SaO}_{2}$ or clinical score with regular nebulised salbutamol and/or ipratropium bromide in infants with mild bronchiolitis. ${ }^{42}$ Ho et al found a fall in $\mathrm{SaO}_{2}$ with nebulised salbutamol in RSV positive infants. ${ }^{43}$ Sanchez et al compared salbutamol to nebulised racemic adrenaline in patients with acute bronchiolitis. Salbutamol had no effect on clinical score, $\mathrm{SaO}_{2}$, or respiratory resistance. Adrenaline improved respiratory rate and inspiratory and expiratory resistance. ${ }^{44}$ There is no clear evidence that oral or intravenous aminophylline is beneficial in bronchiolitis. 4546

How should we interpret these results? What does a change in clinical score or lung mechanics after one or two doses of a 
bronchodilator mean in an illness that lasts for days? There is no convincing evidence that bronchodilators produce a clinically significant improvement in infants with viral bronchiolitis. ${ }^{33-35} \mathrm{We}$ do not routinely use them in bronchiolitis. A trial of nebulised salbutamol or ipratropium is reasonable in older infants where distinction from asthma may be difficult, or in children with bronchiolitis and bronchopulmonary dysplasia, who sometimes respond. Because bronchodilators may worsen hypoxaemia in wheezy infants, we strongly recommend that they are given in oxygen and that careful clinical and $\mathrm{SaO}_{2}$ monitoring is used to assess their effect.

\section{RIBAVIRIN}

Ribavirin is a synthetic nucleoside with virostatic activity against many viruses including RSV. An aerosol from a small particle aerosol generator is delivered to a headbox, facemask, or oxygen tent for 12-20 hours a day for 3-5 days. It can be given through a ventilator circuit if valves are used in the inspiratory lines, a breathing circuit filter is placed in the expiratory line, and filters are replaced regularly to prevent deposition of the drug within the ventilator. ${ }^{4748}$ Side effects are rare in patients or health workers. ${ }^{49}$ Because of a theoretical risk of teratogenicity, pregnant women should avoid exposure to ribavirin. ${ }^{15}$

Early studies of ribavirin in RSV bronchiolitis showed improved clinical signs and oxygenation. However, the design of these studies was flawed. ${ }^{50} 51$ In previously well children with bronchiolitis, there is no convincing evidence ribavirin expedites recovery or reduces complications.

The American Academy of Pediatrics has recommended the use of ribavirin in certain infants with RSV infection. ${ }^{15}$ These include infants with congenital heart or chronic lung disease, impaired, multiple abnormalities, preterm infants and those less than 6 weeks of age, and infants ventilated for RSV infection. Few British paediatricians follow this advice. We are unconvinced there is evidence to support these indications. For example, while prematurity and young age are risk factors for severe disease, we do not know that giving ribavirin to infants with these factors is beneficial. Similarly, the value of ribavirin in ventilated children is unclear.

Several studies have suggested that ribavirin may benefit infants with bronchiolitis and underlying cardiopulmonary disease. ${ }^{50}$ In babies with bronchopulmonary dysplasia or heart disease, clinical scores improved more rapidly in those given ribavirin, but there was no reduction in hospital stay or need for oxygen. ${ }^{52}$ In another study, high risk infants with RSV infection were treated with ribavirin and their outcome was compared with unmatched low risk 'controls'. ${ }^{53}$ There was more rapid clinical improvement and fewer days of ventilation with ribavirin, but the two groups were too dissimilar to draw any conclusions. Groothuis et al studied early ribavirin treatment in children with RSV infection and bronchopulmonary dysplasia or heart disease. ${ }^{54}$ After three days, the improvements in $\mathrm{SaO}_{2}$ and oxygen needs were greater with ribavirin than placebo. Respiratory scores and duration of hospital stay were not improved.

Only one study has shown a benefit of ribavirin on the duration of ventilation. ${ }^{48}$ Ventilated infants with RSV infection were randomised to receive either ribavirin or sterile water aerosols. The duration of ventilation, supplementary oxygen, and hospital stay were markedly less in the ribavirin group. Unfortunately, this study used nebulised water, a known bronchial irritant, as placebo. ${ }^{55}$ The mean length of ventilation in the placebo group was 10 days, but other studies have reported a mean length of ventilation of four days in infants not given ribavirin. ${ }^{14}$ It is possible the nebulised water prolonged ventilation in the placebo group. Another similar study of ventilated infants compared ribavirin with saline aerosol: ribavirin and placebo patients did not differ in the duration of ventilation, oxygen treatment, or hospital stay. ${ }^{47}$ Both studies excluded infants presenting with apnoea: we know of no studies that show ribavirin reduces apnoea.

In 1988, Isaacs and others made a strong case for a multicentre controlled trial of nebulised ribavirin in infants with cardiopulmonary disease and babies under 6 weeks old who developed RSV infection. ${ }^{51}$ The need for such a trial remains, given the uncertain efficacy and the significant cost of ribavirin. Until then, we will use ribavirin in patients with proved RSV infection and cystic fibrosis, severe immunodeficiency, congenital heart disease and pulmonary hypertension, and in infants with bronchopulmonary dysplasia and pre-existing oxygen dependence.

\section{CORTICOSTEROIDS}

Corticosteroids are of no value in viral bronchiolitis. In a controlled study, betamethasone had no effect on respiratory signs or length of admission. ${ }^{56} \mathrm{Tal}$ et al reported a benefit in children given dexamethasone plus salbutamol, but this study included children with asthma. ${ }^{57}$ In a recent study, infants with bronchiolitis received intravenous hydrocortisone and oral prednisolone, or placebo. Steroids had no effect on length of admission, lung function, or clinical recovery. ${ }^{58}$

\section{ANTIBIOTICS}

Acute bronchiolitis is always viral in origin. Hall et al showed that the risk of secondary bacterial infection in children who had no underlying pulmonary or immune disorder was less than $2 \%$ in 565 hospitalised infants with RSV infection. ${ }^{59}$ Although secondary infection is uncommon, dual infection with RSV and bacteria or other organisms should be considered if there are atypical clinical or radiological features. For example we recently treated an infant with RSV bronchiolitis and severe hypoxaemia requiring mechanical ventilation. As the chest radiograph and the 
clinical course were not typical of bronchiolitis, other organisms were urgently sought. $C$ trachomatis was identified in nasal and tracheal secretions and erythromycin was started. Thirteen RSV positive infants in the study of Hall et al had concurrent bacterial infection (for example meningitis, urinary tract infection) at presentation. ${ }^{59}$

We give antibiotics to all infants who present with recurrent apnoea, particularly if there is circulatory impairment, as the possibility of septicaemia cannot be excluded. We would consider antibiotics in infants with an acute clinical deterioration, a high white cell count, a raised $C$ reactive protein, or progressive infiltrative changes on chest radiography. ${ }^{60}$ We favour intravenous cefotaxime, adding erythromycin if there is evidence of chlamydial infection.

\section{ASSISTED VENTILATION}

The decision to ventilate an infant with bronchiolitis is based primarily on clinical grounds. Recurrent apnoea with severe oxygen desaturation and progressive or persistent acidosis $(\mathrm{pH}<7 \cdot 20)$, are absolute indications for ventilation. We would ventilate most infants with a combination of disturbed conscious level, deteriorating chest movement, and persistently low $\mathrm{SaO}_{2}$ levels $(<85 \%)$ despite high inspired oxygen concentrations $(>60 \%)$. Increasing tachypnoea and tachycardia indicate deterioration but are not in themselves indications for ventilation. There is no absolute value of arterial carbon dioxide tension that indicates the need for ventilation: infants with levels greater than $12 \mathrm{kPa}$ have been managed without ventilation. ${ }^{1}$

There needs to be close cooperation between paediatricians, anaesthetists, and nursing staff. We mainly use time cycled pressure limited ventilators. In older infants and those with severe atelectasis, we use time cycled volume controlled ventilators (Siemens Servo 900C). We have not found nasopharyngeal continuous positive airways pressure useful in avoiding the need for full ventilation.

Ventilator settings are tailored to the patient's needs and blood gases. Expiration is dependent on airway resistance and pulmonary compliance. Infants with bronchiolitis have poor compliance and increased resistance. Adequate expiratory times are needed to allow expiration and avoid hyperinflation. We use slow rates (10-25 breaths/min) with long expiratory times (2-3 seconds). Because of decreased compliance, relatively long inspiratory times (1-1.5 seconds) are used. Peak inspiratory pressures are kept as low as possible but pressures over $40 \mathrm{~cm} \mathrm{H}_{2} \mathrm{O}$ may be needed. ${ }^{61}$ The value of positive end expiratory pressure is unproved and it may be harmful. ${ }^{62}$ We aim to maintain arterial $\mathrm{pH}$ greater than $7 \cdot 28$ and arterial oxygen tension greater than $10 \mathrm{kPa}$. It is not necessary to increase ventilation to achieve normal arterial carbon dioxide tension levels. Provided a high carbon dioxide tension does not reflect tube blockage, pneumothorax or ventilator failure, and as long as the arterial $\mathrm{pH}$ is acceptable, we accept high levels of carbon dioxide tension.

An active approach to weaning from ventilation is important. Endotracheal intubation leads to retained secretions, atelectasis, and fluctuating degrees of hypoxaemia due to ventilation-perfusion mismatch: this problem worsens with prolonged ventilation and the use of muscle relaxants. Once oxygen requirements are $40-50 \%$ or less and peak inspiratory pressures are less than $20-22 \mathrm{~cm} \mathrm{H}_{2} \mathrm{O}$, we change to endotracheal continuous positive airways pressure $\left(4-7 \mathrm{~cm} \mathrm{H}_{2} \mathrm{O}\right.$ ). If the infant is stable for 8-12 hours we then extubate.

Most of our ventilated infants are initially sedated with a continuous infusion of midazolam for 12-24 hours. We avoid prolonged use of midazolam because we are concerned about possible neurotoxicity. For further sedation we use nasogastric chloral hydrate or intravenous morphine. Neuromuscular blockade with atracurium is used in infants who need high inspiratory pressures and in those in whom distress is preventing effective ventilation. Fluids are restricted to $60-80 \mathrm{ml} / \mathrm{kg} /$ day. Nasogastric milk is started as early as possible, usually after the first 24 hours of ventilation. Although secondary bacterial infection is uncommon, most infants we ventilate receive antibiotics because of infiltrates on the chest radiograph.

In infants whose condition deteriorates despite maximal ventilator support, extracorporeal membrane oxygenation (ECMO) should be considered. A preliminary report of ECMO in 12 infants with bronchiolitis and refractory hypoxia despite maximal ventilation is encouraging. ${ }^{63}$ Seven infants survived: associated bronchopulmonary dysplasia did not predict a worse outcome. The results of clinical trials in the $\mathrm{UK}$ and from North America may clarify the role of ECMO in bronchiolitis.

\section{SEDATION}

Agitation should suggest hypoxia and the need for oxygen. We do not use sedation except during ventilation. High doses of chloral hydrate $(70-100 \mathrm{mg} / \mathrm{kg}$ ) can cause a fall in oxygen saturation with respiratory depression. ${ }^{64}$ There is no evidence that lower doses help or harm. Parents and skilled nurses are important in allaying anxiety.

\section{PHYSIOTHERAPY}

Babies with respiratory distress often show a fall in $\mathrm{SaO}_{2}$ when handled or upset. Minimal handling is an important aspect of care. Physiotherapy, which is still used in some units for infants with bronchiolitis, is not only of no benefit, but may cause deterioration. ${ }^{65}$

\section{Conclusions}

Over 30 years ago, Reynolds and Cooke wrote that 'oxygen is vitally important in bronchiolitis: there is little evidence that any other treatment is useful'. ${ }^{66}$ This statement is still 
largely true. We are better at diagnosing and assessing the illness and at limiting the damage of complications such as respiratory failure or cross infection. Novel therapies such as passive immunisation with high titre RSV immunoglobulin ${ }^{6768}$ may prove to be helpful in the future. But there is currently no treatment which has convincingly been shown to reduce the severity or duration of viral bronchiolitis in the majority of infants. This common condition still merits our respect and close attention.

1 Phelan PD, Landau LI, Olinsky A. Epidemiology and clinical patterns of acute respiratory infection. Respiratory cal patterns of acute respiratory infection. Respir
illness in children. Oxford: Blackwell, 1990: 24-88.

2 Wohl MEB, Chernick V. Bronchiolitis. Am Rev Respir Dis 1978; 118: 759-81.

3 Tristram DA, Miller RW, McMillan JA, Weiner LB. Simultaneous infection with respiratory syncytial viru and other respiratory pathogens. Am $\mathcal{f}$ Dis Child 1988 142: 834-6.

4 Ray CG, Minnich LL, Holberg CJ, et al. Respiratory syncytial virus-associated lower respiratory illnesses: possible influences of other agents. Pediatr Infect Dis $\mathscr{f}$ 1993; 12: 15-9.

5 Seidenberg J, Masters IB, Hudson I, Olinsky A, Phelan PD. Disturbance in respiratory mechanics in infants with Disturbance in respiratory mechanics
bronchiolitis. Thorax $1989 ; 44: 660-7$.

6 Stokes GM, Milner AD, Hodges IGC, Henry RL, Elphick MC. Nebulised therapy in acute severe bronchiolitis in infancy. Arch Dis Child 1983; 58: 279-83.

7 Simpson H, Matthew D, Inglis JM, George EL. Virological findings and blood gas tensions in acute lower respiratory tract infections in children. $B M \mathcal{F} 1974$; ii: $629-32$.

8 Mulholland EK, Olinsky A, Shann FA. Clinical finding and severity of acute bronchiolitis. Lancet 1990; 335 $1259-61$.

9 Anas N, Boettrich C, Hall CB, Brooks JG. The association of apnea and respiratory syncytial virus infection in infants. $\mathcal{F}$ Pediatr 1982; 101: 65-8.

10 Bruhn FW, Mokrohisky ST, McIntosh K. Apnea associated with respiratory syncytial virus infection in young infants. f Pediatr 1977; 90: 382-6.

11 Church NR, Anas NG, Hall CB, Brooks J. Respiratory syncytial virus-related apnea in infants. Am $\mathcal{F}$ Dis Child 1984 138: $247-50$.

12 Hall CB, Powell KR, MacDonald NE, et al. Respiratory syncytial virus infection in children with compromised immune function. $N$ Engl $\mathcal{F}$ Med 1986; 315: 77-81.

13 MacDonald NE, Hall CB, Suffin SC, Alexson C, Harris PJ, Manning JA. Respiratory syncytial virus infection in infants with congenital heart disease. $N$ Engl $f$ Med 1982 307: $397-400$.

14 Stretton M, Ajizian SJ, Mitchell I, Newth CJ. Intensive care course and outcome of patients infected with respiratory syncytial virus. Pediatr Pulmonol 1992; 13: 143-50.

15 American Academy of Pediatrics. Use of ribavirin in the treatment of respiratory syncytial virus infection. Pediatrics 1993; 92: 501-4.

16 Lebel MH, Gauthier M, Lacroix J, Rousseau E, Buithieu M Respiratory failure and mechanical ventilation in sever bronchiolitis. Arch Dis Child 1989; 64: 1431-7.

17 Dawson KP, Lonf A, Kennedy J, Mogridge N. The ches radiograph in acute bronchiolitis. $\mathcal{F}$ Paediatr Child Healt 1990; 26: 209-11.

18 Welliver RC, Cherry JD. Bronchiolitis and infectious asthma. In: Feigin RD, Cherry $\mathrm{JD}$, eds. Textbook of pediatric infectious diseases. 3rd Ed. Philadelphia: WB Saunders, 1992: 245-54.

19 Rivers RPA, Forsling ML, Olver RP. Inappropriate secretion of antidiuretic hormone in infants with respira secretion of antidiuretic hormone in infants with

20 Steensell-Moll HA, Hazelzet JA, van der Voort E, Neijen HJ, Hackeng WHL. Excessive secretion of antidiuretic hormone in infections with respiratory syncytial virus. Arch Dis Child 1990; 65: 1237-9.

21 Madge P, Paton JY, McColl JH, Mackie PLK. Prospective controlled study of four infection-control procedures to prevent nosocomial infection with respiratory syncytial virus. Lancet 1992; 340: 1079-83.

22 Berman S, Simoes EAF, Lanata C. Respiratory rate and pneumonia in infancy. Arch Dis Child 1991; 66: 81-4.

23 Wang EEL, Milner RA, Nava $L_{3}$ Maj H. Observer agreement for respiratory signs and oximetry in infants hospitalised with lower respiratory infections. Am Rev Respir Dis 1992; 145: 106-9.

24 Shaw KN, Bell LM, Sherman NH. Outpatient assessment of infants with bronchiolitis. Am F Dis Child 1991; 145: 151-5.

25 Stebbens VA, Poets CF, Alexander JR, Arrowsmith WA Southall DP. Oxygen saturation and breathing patterns in infancy. 1: Full term infants in the second month of life. infancy. 1: Full term infants in the

26 Southall DP, Samuels M. Inappropriate sensor application in pulse oximetry. Lancet 1992; 340: 481-2.

27 Poets CP, Samuels Home monitoring of transcutaneous oxygen tension in the early detection of hypoxaemia in infants and young children. Arch Dis Child 1991; 66: 676-82.

28 Anonymous. Nosocomial infection with respiratory syncytial virus. Lancet 1992; 340: 1071-72.

29 Isaacs D, Dickson $H$, O'Callaghan C Sheaves $R$, Winter A Moxon ER. Handwashing and cohorting in the prevention of hospital acquired infection with respiratory yncytial virus. Arch Dis Child 1991; 66: 227-31.

30 O'Callaghan C. Prevention of respiratory syncytial virus infection. Lancet 1993; 341: 182.

31 Shann F, Gatchalian S, Hutchinson R. Nasopharyngea oxygen in children. Lancet 1988; ii: 1238-40.

32 Newcombe RW. Use of adrenergic bronchodilators by pediatric allergists and pulmonologists. Am f Dis Child 1989; 143: 481-5.

33 Goodman BT, Chambers TL. Bronchodilators for bronchiolitis? Lancet 1993; 341: 1380.

34 Archivist. Salbutamol in bronchiolitis. Arch Dis Child 1991 66: 1183 .

35 Milner AD, Murray M. Acute bronchiolitis in infancy: reatment and prognosis. Thorax 1989; 44: 1-5.

36 Soto ME, Sly PD, Uren E, Taussig LM, Landau LI. Broncho-dilator response during acute viral bronchioliti in infancy. Pediatr Pulmonol 1985; 1: 85-90.

37 Tepper RS, Rosenberg D, Eigen H, Reister T. Bronchodilator responsiveness in infants with bronchiolitis. Pediatr Pulmonol 1994; 17: 81-5.

38 Mallory GB Jr, Motoyama EK, Koumbourlis AC, Mutich RL, Makayama DK. Bronchial reactivity in infants in acute respiratory failure with viral bronchiolitis. Pediatr Pulmonol 1989; 6: 253-9.

39 Henry RL, Milner AD, Stokes GM. Ineffectiveness of ipratropium bromide in acute brochiolitis. Arch Dis Child 1983; 58: 925-6.

40 Klassen TP, Rowe PC, Suthcliffe T, et al. Randomized tria of salbutamol in acute bronchiolitis. $\mathcal{J}$ Pediatr 1991; 118: 807-11.

41 Schuh S, Canny G, Reisman JJ, et al. Nebulized albuterol in acute bronchiolitis. $\mathcal{F}$ Pediatr 1990; 117: 633-7.

43 Wang EEL, Milner R, Allen U, Maj A. Bronchodilators for treatment of mild bronchiolitis: a factorial randomised trial. Arch Dis Child 1992; 67: 298-93.

43 Ho L, Collis G, Landau LI, Le-Souef PM. Effect of salbutamol on oxygen saturation in bronchiolitis. Arch Dis Child 1991; 66: 1061-4.

44 Sanchez I, Dekoster J, Powell RE, Wolstein R, Chernick V. Effect of racemic epinephrine and salbutamol on clinical score and pulmonary mechanics in infants with bronchiolitis. F Pediatr 1993; 122: 145-51.

45 Brooks LJ, Cropp GJA. Theophylline therapy in bronchiolitis. Am $\mathcal{F}$ Dis Child 1981; 135: 934-6.

46 Schena JA, Crone RK, Thompson JE. The use of aminophylline in severe bronchiolitis. Crit Care Med 1984 12: 225

47 Meert KL, Sarnaik AP, Gelmini MJ, Lieh-Lai MW. Aerosolised ribavirin in mechanically ventilated children with respiratory syncytial virus lower respiratory tract disease: a prospective double blind, randomised trial. Crit Care Med 1994; 22: 566-71.

48 Smith DW, Frankel LR, Mathers LH, Tang ATS, Ariagno Rl, Prober CG. A controlled trial of aerosol ribavirin in infants receiving mechanical ventilation for severe respiratory syncytial virus infection. N Engl f Med 1991; 325: $24-9$.

49 Janai HK, Marks MI, Zaleska M, Stutman HR. Ribavirin adverse drug reactions, 1986-1988. Pediatr Infect Dis $f$ 1990; 9: 209-1

50 Wald ER, Dachefsky B, Green M. In re ribavirin: a case of premature adjudication. f Pediatr 1988; 112: 154-8.

51 Isaacs D, Moxon ER, Harvey $\mathrm{D}$, et al. Ribavirin in respiratory syncytial virus infection. A double blind placebo controlled trial is needed. Arch Dis Child 1988; 63: $986-90$

52 Hall CB, McBride JT, Gala CL, et al. Ribavirin treatment in infants with underlying cardio-pulmonary disease. $¥ A M A$ infants with underlying

53 Conrad DA Christenson JC Waner JA Marks MI Aerosolised ribavirin treatment of respiratory syncytial
virus infection in infants hospitalised during an epidemic. virus infection in infants hospitalised
Pediatr Infect Dis $¥ 1987 ; 6: 152-8$.

54 Groothuis JR, Gutierrez KM, Lauer BA. Respiratory syncytial virus infections in children with bronchopulmonary dysplasia. Pediatrics 1988; 82: 119-23.

55 Moler FW, Brandy KP, Custer JR. Ribavirin for severe RSV infection. N Engl $\mathcal{Y}$ Med 1991; 325: 1884.

56 Leer JA, Bloomfield NJ, Green JL, et al. Corticosteroid treatment in bronchiolitis: a controlled collaborative study in 297 infants and children. Am $\mathcal{F}$ Dis Child 1969; 117, 495-503.

57 Tal A, Babilski C, Yohai D, et al. Dexamethasone and salbutamol in the treatment of acute wheezing in infants. Pediatrics 1983; 71: 13-8.

58 Springer C, Bar-Yishay E, Uwayyed $\mathrm{K}$, et al. Corticosteroids do not affect the clinical or physiological status of infants with bronchiolitis. Pediatr Pulmonol 1990 9: $181-5$.

59 Hall CB, Powell KR, Schnabel KC, Gala CL, Pincus PH Risk of secondary bacterial infection in infants hospi-
talised with respiratory syncytial virus infection. $₹$ Pediatr talised with respirat

60 Ruuskanen O, Putto A, Sarkkinen H, Meurman O, Iriala K. C-reactive protein in respiratory virus infection. $f$ Pediat C-reactive protein in

61 Frankel LR, Lewiston NJ, Smith DW, Stevenson DK. Clinical observations on mechanical ventilation for 
respiratory failure in bronchiolitis. Pediatr Pulmonol 1986; 2: 307-11.

62 Smith PJ, El Khatib MF, Carlo WA. PEEP does not improve pulmonary mechanics in infants with bronchiolitis. Am Rev Respir Dis 1993; 147: 1295-8.

63 Steinhorn RH, Green TP. Use of extra corporeal membrane oxygenation in the treatment of respiratory syncytial virus bronchiolitis: the national experience, 1983-1988. f Pediatr 1990; 116: 337-42.

64 Mallol J, Sly PD. Effect of chloral hydrate on arterial oxygen saturation in wheezy infants. Pediatr Pulmonol 1988; 5: 96-9.
65 Webb MSC, Martin JA, Cartlidge PHT, Ng YK, Wright NA. Chest physiotherapy in acute bronchiolitis. Arch Dis NA. Chest physiotherapy

66 Reynolds EOR, Cooke CD. The treatment of bronchiolitis. f Pediatr 1963; 63: 1205-7.

67 Groothuis JR, Simoes EAF, Levin MJ, et al. Prophylactic administration of respiratory syncytial virus immunoglob ulin to high risk infants and young children. $N$ Engl f Med 1993; 329: 1524-30.

68 Levin MJ. Treatment and prevention options for respiratory syncytial virus infections. $\mathcal{f}$ Pediatr 1994; 124: S22-7.

\section{Screening for neuroblastoma - biological characteristics of the tumours}

Mass screening of 6 month old children for neuroblastoma using urinary catecholamine analyses was started in Japan in 1985. The tumours detected appeared to have a good prognosis and overall mortality from the disease did not fall (see Archivist 1991; 66: 1007). A recent paper (Sachiyo Suita and colleagues, fournal of Pediatric Surgery 1994; 29: 599-603) gives more information about these tumours.

Between 1985 and 1990 in the Kyushu area of Japan there were 199 newly diagnosed cases of neuroblastoma. Ninety four of these had advanced disease (stages III and IV) and are the subject of this paper. Of these 94,18 had been detected through the screening programme and 76 presented clinically.

The tumours detected by mass screening and those detected clinically differed considerably in their biological characteristics. Thus the following favourable features were found in the mass screening group: no $\mathrm{N}$-myc oncogene amplification (14 of 18), favourable histological classification (10 of 10), aneuploid nuclear DNA content (three of three), and S-100 protein positive (three of three). In the non-mass screening group the findings were: no $\mathrm{N}-m y c$ oncogene amplification (30 of 45), favourable histology (four of 15), aneuploid nuclear DNA content (three of 10 ), and S-100 protein positive (11 of 21).

Treatment in the mass screening group was variable but generally less aggressive than in the patients who presented clinically. Nevertheless, there were no deaths in the first group but fewer than a quarter of the second group survived for four years.

There seems no doubt, therefore, that the tumours detected by screening are different and carry a much better prognosis. Whether they would regress without treatment is still uncertain. The authors suggest a treatment approach to these tumours including less aggressive chemotherapy. They do not appear to consider the possibility of abandoning the screening programme. Whether repeated or later screening would be more beneficial is not known. 